\title{
Implementasi Honey Bee Mating Optimization Pada Vehicle Routing Problem with Time Windows Dalam Perencanaan Jalur Wisata Malang
}

\author{
M. Syawaluddin Putra Jaya ${ }^{*}$, Yufiz Azhar ${ }^{2}$, Nur Hayatin ${ }^{3}$ \\ 1,2,3Teknik Informatika/Universitas Muhammadiyah Malang \\ inijaya24@gmail.com*
}

\begin{abstract}
Abstrak
Vahicle Routing Problem adalah suatu masalah pencaian jalur yang akan dilalui dengan tujuan mencari rute yang paling cepat atau pendek. Vahicle Routing Problem with Time Windows (VRPTW) yang merupakan sebutan bagi VRP dengan kendala tambahan berupa adanya time windows pada masing-masing pelanggan yang dalam hal ini berupa destinasi wisata. Dalam penelitian ini diterapkan Honey Bee Mating Optimization (HBMO) dalam menyelesaikan VRPTW. HBMO sendiri terinspirasi oleh perilaku koloni lebah ketika bereproduksi. Algoritma tersebut bertujuan untuk mengevaluasi pencarian individu atau solusi terbaik. Tujuan dari penelitian ini adalah bagaimana mengimplementasikan Honey Bee Mating Optimization dalam menyelesaikan VRPTW pada perencanaan jalur wisata di Malang. Sehingga dapat meminimumkan waktu dan jarak tempuh perjalanan. Berdasarkan hasil pengujian, parameter yang optimal untuk optimasi VRPTW menggunakan HBMO pada kasus perencannan jalur wisata Malang yaitu dengan menggunakan 800 generasi, populasi lebah jantan sebesar 300, batas kapasitas spermatheca sejumlah 100 , nilai mutation ratio $\left(P_{m}\right)$ dan royal jelly masing-masing bernilai 0.5 .
\end{abstract}

Kata Kunci: Vehicle Routing Problem, Honey Bee Mating Optimization, Optimasi, Jalur Wisata

\section{Abstract}

Vahicle Routing Problem is a problem of finding the best route that will be passed with the purpose to finding the fastest or shortest route. Vahicle Routing Problem with Time Windows (VRPTW) is a part of VRP with additional obstacles in the form of time windows in each customer. In this research, Honey Bee Mating Optimization (HBMO) was applied to completing VRPTW. $H B M O$ itself was inspired by the behavior of bee colonies when reproducing. The purpose of this algorithm is to evaluate the best individual or the best solutions. The purpose of this research is how to implement Honey Bee Mating Optimization to completing VRPTW in Malang tourism route planning. So that it can minimize travel time and distance. Based on the results of the testing, the optimal parameters for VRPTW optimization using HBMO in Malang tourism route planning case are using 800 generations, the male bee population is 300, the capacity limit of spermatheca is 100 , the mutation ratio $\left(P_{m}\right)$ and royal jelly are respectively 0.5 .

Keywords: Vehicle Routing Problem, Honey Bee Mating Optimization, Optimization, Tourist Paths

\section{Pendahuluan}

Pariwisata merupakan sektor yang sangat penting dalam mendukung perkembangan suatu daerah, sektor ini turut serta menyumbangkan banyak pemasukan untuk APBD khususnya bagi daerah yang mempunyai banyak potensi wisata seperti di Malang. Kota ini memiliki potensi wisata baik berupa wisata alam, budaya dan sejarah. Berdasarkan data Disbudpar Kota Malang, terdapat peningkatkan jumlah wisatawan yang cukup signifikan selama dua tahun terakhir ini. Pada tahun 2015 tercatat 3.290 .067 wisatawan domestik yang masuk ke Kota Malang, sedangkan wisatawan mancanegara berjumlah 8.265 pengunjung. Tahun 2016 terjadi lonjakan pengunjung yang tergolong signifikan karena jumlahnya naik menjadi 3.987.074 untuk wisatawan domestik, dan wisatawan mancanegara berjumlah 9.535 orang [1].

Dalam melakukan perjalanan wisata, aspek yang perlu diperhatikan adalah bagaimana mengatur penggunaan waktu atau jarak transportasi seoptimal mungkin, salah satu cara untuk mengatasi hal tersebut adalah menentukan rute optimal perjalanan wisata. Permasalahan yang memiliki tujuan untuk mencari jalur atau rute yang paling cepat atau pendek, untuk suatu 
kendaraan, agar dapat sampai ke sejumlah tujuan yang berangkat dan berakhir di titik yang sama disebut sebagai Vehicle Routing Problem (VRP).

Vahicle Routing Problem with Time Windows (VRPTW) merupakan salah satu pengembangan dari VRP dengan kendala tambahan berupa adanya time windows pada masingmasing tujuan yang dalam hal ini berupa destinasi wisata. Waktu ketersediaan pada setiap tempat dapat berbeda-beda dan dinyatakan dalam selang waktu berupa batas waktu awal sampai waktu akhir pelayanan [2].

Dalam penelitian ini diterapkan metode metaheuristic yaitu Honey Bee Mating Optimization (HBMO) dalam menyelesaikan VRPTW. Dalam penelitian yang dilakukan oleh Felix Arya Gunadi, Cynthia Prithadevi Juwono dan Hanky Fransiscus, metaheuristic merupakan metode tingkat lanjut (advanced) berbasis heuristik untuk mengatasi permasalahan optimasi secara efisien. Metode metaheuristik mempunyai kemampuan mencari solusi di dalam ruang yang lebih luas karena mempunyai mekanisme eksploitasi dan eksplorasi. Alasan dari penggunaan metode metaheuristik yaitu metode ini dapat menghasilkan solusi yang lebih baik dari metode heuristik dan lebih cepat dalam hal penyelesaian [3].

Pada penelitian Yannis Marinakis, Magdalene Marinaki dan Georgios Dounias, HBMO sendiri terinspirasi oleh perilaku koloni lebah ketika bereproduksi. Algoritma tersebut bertujuan untuk mengevaluasi pencarian individu atau solusi terbaik. Dalam rangkaian dengan contoh benchmark klasik yang diajukan oleh Christo $\mathrm{Fi}$ Des, kualitas rata-rata adalah 0,029\% dan, dengan demikian, algoritma tersebut berada di peringkat kedua di antara algoritma metaheuristik yang paling dikenal dan di tempat pertama di antara metode terinspirasi alam untuk solusi VRP. Pada set kedua contoh yang diajukan oleh Golden, kualitas rata-rata adalah $0,40 \%$ dan, dengan demikian, algoritma tersebut berada di peringkat kedua di antara algoritma metaheuristik yang paling dikenal dan di tempat kedua di antara metode terinspirasi alam yang digunakan untuk solusi VRP [4].

Tujuan dari penelitian ini adalah bagaimana mengimplementasikan Honey Bee Mating Optimization dalam menyelesaikan VRPTW pada perencanaan jalur wisata di Malang. Dengan mempertimbangkan parameter tiap-tiap tujuan agar didapat solusi global yang optimal, sehingga dapat meminimumkan jarak atau waktu tempuh perjalanan.

\section{Metodelogi penelitian}

Metode yang digunakan dalam penelitian ini terdiri dari beberapa tahapan yaitu dimulai dari tahap studi pustaka dan identifikasi masalah, tahap pengumpulan data, tahap perancangan program, tahap implementasi, tahap analisa dan evaluasi, dan tahap kesimpulan dan saran.

\subsection{Studi Pustaka dan Identifikasi Masalah}

Pada tahap ini penulis melakukan studi pustaka untuk mencari dasar teori penelitian serta untuk menambah pengetahuan tentang metode yang akan digunakan selama penelitian seperti teori tentang Vahicle Routing Problem with Time Windows (VRPTW) dan Honey Bee Mating Optimization (HBMO), simulated annealing dan perbandingan dengan penelitian sebelumnya.

\subsection{Pengumpulan Data}

Pada tahap ini dilakukan pengumpulan data penginapan sebagai titik awal dan akhir rute perjalanan dan data destinasi wisata yang diperlukan untuk penelitian yang didapatkan dari google maps, adapun data-data destinasi wisata yang diperlukan sebagai berikut:

1. Waktu buka

2. Waktu tutup

3. Rata-rata durasi kunjungan

4. Jarak dan waktu tempuh antar node

Dengan catatan waktu buka dan waktu tutup suatu destinasi dianggap sama untuk setiap hari. Sebelum digunakan ke dalam program, data waktu buka-tutup dikalikan dengan 60 untuk mempermudah perhitungan dalam mencari nilai fitness.

Jarak antar node atau lokasi wisata dan waktu tempuh antar node digambarkan dalam matriks kedekatan graf berarah dan berbobot. Data jarak dan waktu antar lokasi dibedakan menjadi masing-masing 2 tabel, yaitu:

1. tabel jarak saat normal

2. tabel jarak saat padat

3. tabel waktu saat normal

REPOSITOR, Vol. 2, No. 4, April 2020: 495-502 
4. tabel waktu saat padat

Pengambilan data padat dilakukan pada interval jam 7.00 - 8.00, 11.00 - 13.00, dan 16.00

- 18.00 (WIB) dan data normal diambil di luar interval tersebut.

\subsection{Perancangan Program}

Pada tahap ini akan dilakukan perancangan program untuk menerapkan Honey Bee Mating Optimization untuk mengatasi VRPTW ke dalam bahasa yang dimengerti oleh komputer, dalah penelitian ini penulis akan menerapkan algoritma pada bahasa pemrograman Java. Tahap ini meliputi tahapan analisis, desain, coding, dan pengujian. Secara sederhana program akan menerima input berupa:

- tujuan wisata Adapun parameter pengujian yang harus di tentukan, antara lain:

- M : jumlah lebah jantan

- Nsperm : kapasitas spermatheca

- $P_{m} \quad$ : mutation ratio

- $\varepsilon \quad$ : variasi mutasi/ royal jelly

- Jumlah iterasi atau generasi

Output:

- Rute wisata terbaik

- urutan nama destinasi wisata

- jumlah hari yang diperlukan untuk melakukan perjalanan tersebut

\subsection{Implementasi Algoritma}

Pada Gambar 1, tahap ini penulis menentukan parameter pengujian dan menggunakan Honey Bee Mating Optimization (HBMO). Algoritma ini terinspirasi oleh perilaku koloni lebah ketika bereproduksi, metode ini menjadi penentu dalam menentukan solusi terbaik untuk mengatasi VRPTW dalam perencanaan jalur wisata di Malang. Algoritma HBMO yang digunakan dalam penelitian ini terdiri dari sejumlah tahapan, yaitu inisiasi genotype (Drone dan ratu), flight mating, proses pembuahan/ crossover, mutasi bayi lebah, dan pemilihan ratu baru berdasarkan nilai fitness [8].

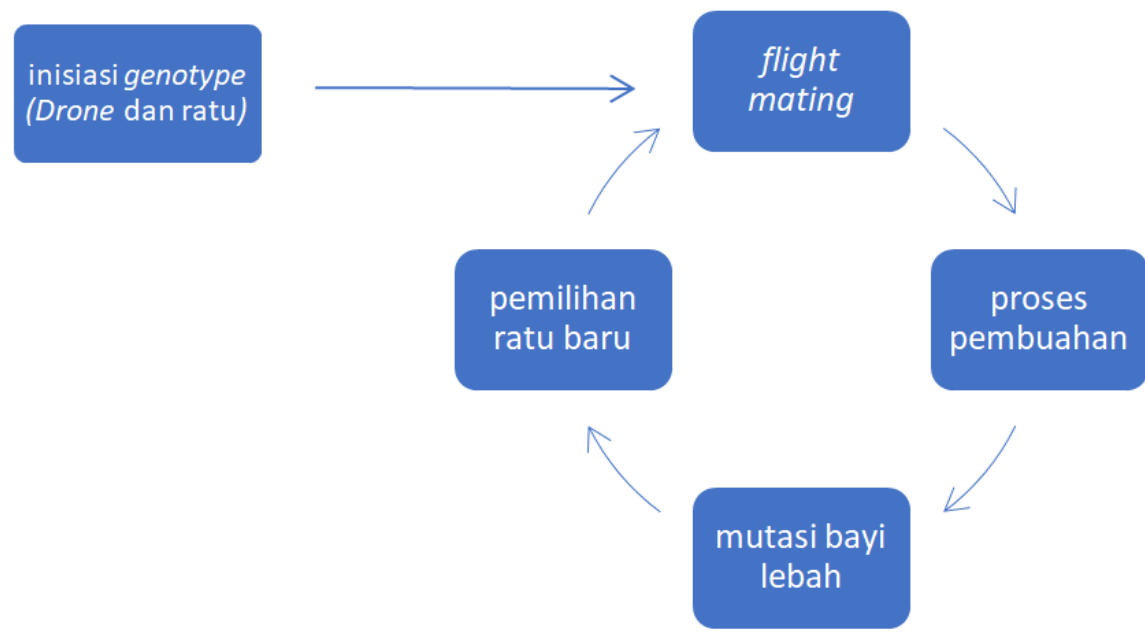

Gambar 1. Tahapan HBMO

\subsection{Analisa dan Evaluasi Model}

Dalam penelitian ini digunakan beberapa skenario uji coba dengan beberapa asusmsi. Uji coba dilakukan dengan menggunakan 20 data destinasi dari daftar destinasi wisata Malang. Lama kunjungan setiap tempat ditentukan dari data buka-tutup kolom ke-3. Jarak antar tempat dan waktu tempuh antar tempat didapat dari data jarak dan waktu yang terdiri dari masing-masing 2 kondisi yaitu kondisi normal dan kondisi padat. Kondisi padat digunakan pada interval jam 7.00 - 8.00, 11.00 - 13.00, dan 16.00 - 18.00 (WIB) dan kondisi normal digunakan di luar interval tersebut. Skenario pengujian yang akan dilakukan adalah: 
1. Pengujian jumlah generasi atau iterasi yang optimal untuk algorotma HBMO VRPTW pada perencanaan jalur wisata di Malang.

2. Pengujian jumlah populasi lebah jantan yang optimal untuk algoritma HBMO VRPTW pada perencanaan jalur wisata di Malang.

3. Pengujian jumlah kapasitas spermatheca yang optimal untuk algoritma HBMO VRPTW pada perencanaan jalur wisata di Malang.

4. Pengjian nilai mutation ratio $\left(P_{m}\right)$ yang terbaik untuk permasalahan VPRTW pada perencanaan jalur wisata di Malang.

\section{Hasil dan Analisa Pengujian}

\subsection{Hasil dan Pengujian Generasi}

Pengujian generasi atau iterasi adalah pengujian yang bertujuan mencari jumlah generasi optimum untuk menyelesaikan masalah VRPTW pada kasus pencarian rute wisata Malang menggunkan algoritma HBMO. Jumlah generasi yang diuji adalah kelipatan 200 mulai dari 200 sampai 1600 generasi. Nilai fitness uji generasi didapat dari rata-rata 10 kali percobaan berulang. Jumlah lebah jantan yang digunakan adalah 100 , kapasitas spermatheca adalah 50 , mutation ratio $\left(P_{m}\right)$ dengan nilai 0.5 dan royal jelly dengan nilai 0.5 .

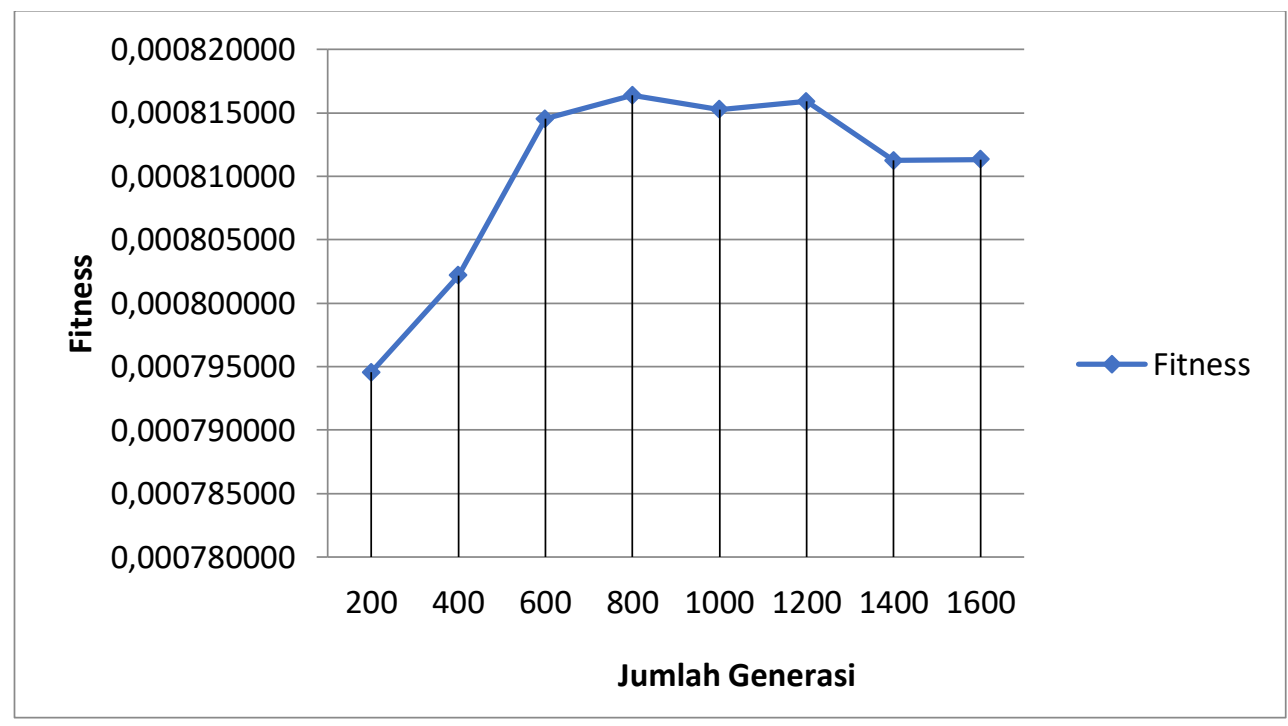

Gambar 2. Grafik Pengaruh Jumlah Generasi Terhadap Nilai Fitness

Gambar 2 menujukkan hasil dari pengujian jumlah generasi dimana proses pencarian solusi dipengaruhi oleh jumlah generasi. Nilai fitness paling rendah berada pada jumlah generasi 200 yaitu dengan rata-rata 0.000794558 . nilai fitness tertinggi terdapat pada jumlah generasi 800 dengan nilai rata-rata 0.000816378 . nilai fitness terendah terdapat pada jumlah generasi paling rendah. Hal ini disebabkan karena algoritma HBMO belum dapat melakukan proses secara optimal karena kurangnya jumlah generasi. Jumlah generasi yang terlalu banyak akan menyebabkan total waktu proses menjadi lebih lama dan nilai fitness yang dihasilkan belum tentu lebih baik. Pada pengujian ini, nilai fitness mencapai titik optimal pada jumlah generasi 800 dan mulai menurun setelah jumlah generasi tersebut. Kesimpulan yang didapat dari pengujian ini adalah jumlah generasi yang optimal untuk mengatasi VRPTW pada kasus pencarian rute wisata Malang yaitu 800 generasi.

\subsection{Hasil dan Pengujian Populasi Lebah Jantan}

Pengujian populasi lebah jantan adalah pengujian yang bertujuan mencari jumlah populasi optimum. Jumlah populasi yang diuji adalah kelipatan 50 mulai dari 150 sampai 400 populasi. Nilai fitness uji populasi didapat dari rata-rata 10 kali percobaan berulang. Jumlah generasi atau iterasi yang digunakan adalah 800 , kapasitas spermatheca adalah 50 , nilai mutation ratio $\left(P_{m}\right)$ dan royal jelly masing-masing bernilai 0.5 . 


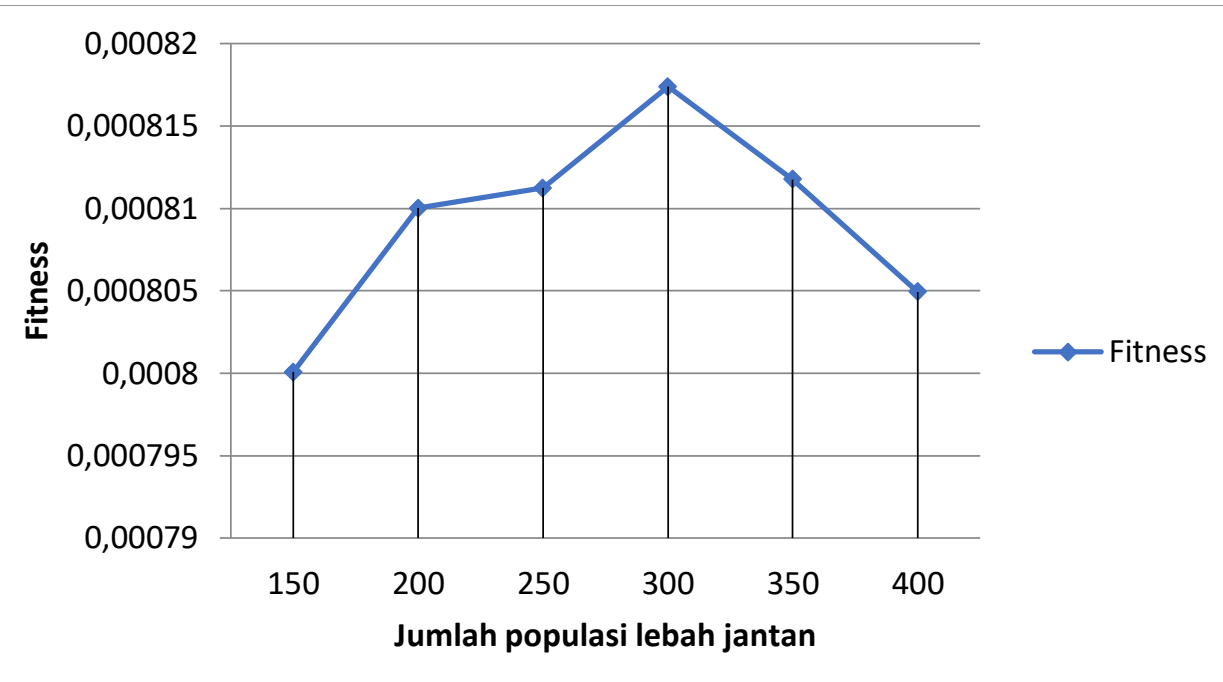

Gambar 3. Grafik Pengaruh Jumlah Populasi Lebah Jantan Terhadap Nilai Fitness

Gambar 3 menujukkan hasil dari pengujian pengaruh populasi lebah jantan terhadap nilai fitness. Pada jumlah populasi 150, nilai fitness yang diperoleh merupakan nilai yang paling rendah yaitu 0.000800076 . nilai fitness tertinggi terdapat pada jumlah populasi 300 dengan nilai 0.000817393 . sama halnya dengan generasi. Populasi yang terlalu sedikit menyebabkan sedikitnya pilihan solusi sehingga membuat nilai fitness yang dihasilkan belum optimal. Sebaliknya, jika jumlah populasi semakin banyak belum tentu menghasilkan nilai fitness yang lebih baik. Hal ini dapat dilihat dari grafik dimana nilai fitness tertinggi didapat pada populasi 300 dan mulai menurun setelahnya. Maka dapat disimpulkan bahwa jumlah populasi lebah jantan yang optimal untuk kasus penelitian ini adalah 300 populasi.

\subsection{Hasil dan Pengujian Kapasitas Spermatheca}

Pengujian kapasitas spermatheca merupakan pengujian untuk mencari jumlah optimum lebah jantan yang akan melakukan perkawinan dengan lebah ratu. Batas kapasitas yang diuji adalah kelipatan 25 mulai dari 50 sampai 200. Nilai fitness uji populasi didapat dari rata-rata 10 kali percobaan berulang. Jumlah generasi atau iterasi yang digunakan adalah 800 , jumlah populasi lebah jantan adalah 300 , nilai mutation ratio $\left(P_{m}\right)$ dan royal jelly masing-masing bernilai 0.5 .

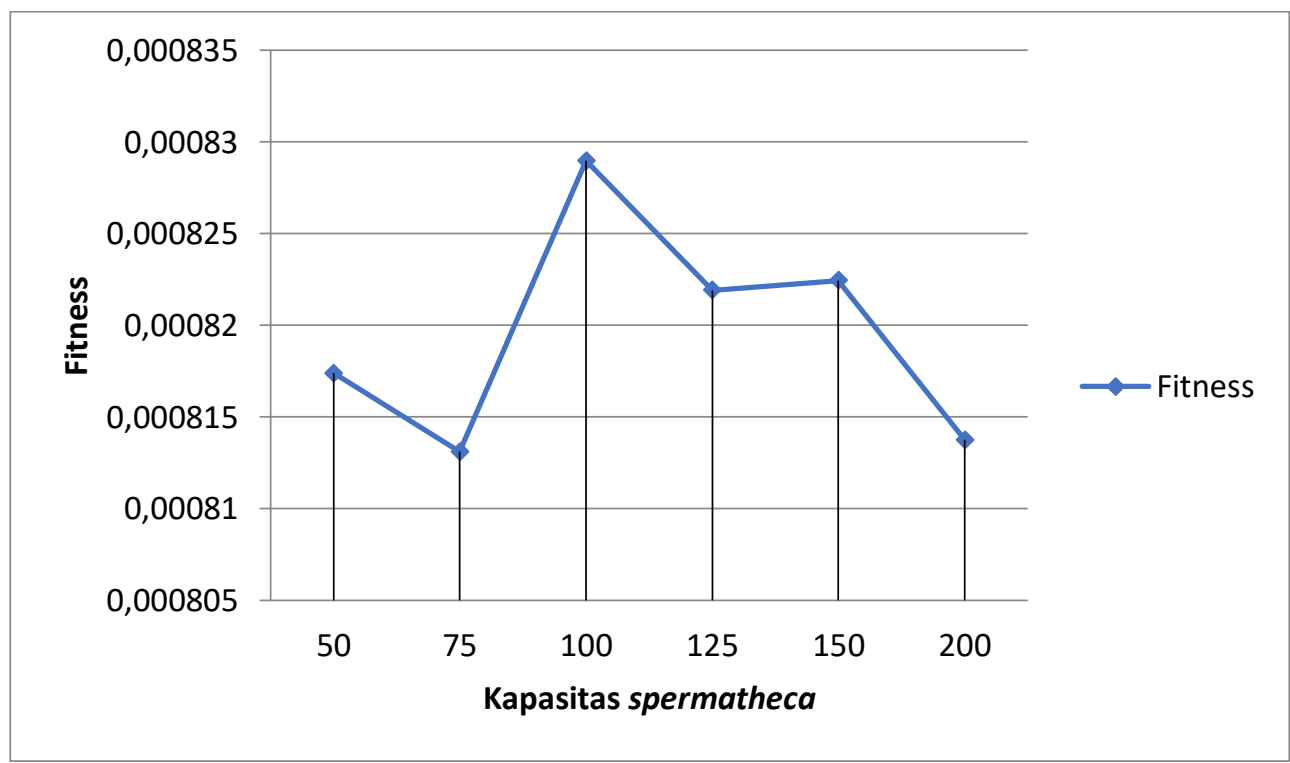

Gambar 4. Grafik Pengaruh Kapasitas Spermatheca Terhadap Nilai Fitness 
Gambar 4 menujukkan hasil dari pengujian pengaruh kapasitas spermatheca terhadap nilai fitness. Pada kapasitas bernilai 75, nilai fitness yang diperoleh merupakan nilai yang paling rendah yaitu 0.000813110 . nilai fitness tertinggi terdapat pada kapasistas bernilai 100 dengan nilai 0.000828974 . kapasitas yang sedikit menyebabkan lebih sedikit perubahan geberagaman individu hasil perkawinan dan mutasi sehingga membuat nilai fitness yang dihasilkan kurang optimal. Sebaliknya, jika kapasitas semakin banyak maka semakin banyak pula lebah jantan yang melakukan perkawinan dengan ratu, sehingga perubahan genotype pada generasi selanjutnya terlalu besar dan berimbas pada penurunan kualitas genotype. Hal ini dapat dilihat dari grafik dimana nilai fitness tertinggi didapat pada kapasitas bernilai 100 dan mengalami penurunan setelah kapasitas tersebut. Maka dapat disimpulkan bahwa jumlah kapasitas spermatheca yang optimal adalah 100 dengan rata-rata nilai fitness sebesar 0.000828974 .

\subsection{Hasil dan Pengujian Mutation Ratio}

Pengujian ini bertujuan untuk menemukan nilai mutation ratio $\left(P_{m}\right)$ optimum pada penerapan algortima HBMO. Nilai kelipatan yang diuji adalah sebesar 0.1 mulai dari 0.1 sampai 1. Nilai fitness pengujian didapat dari rata-rata 10 kali percobaan berulang. Jumlah generasi atau iterasi yang digunakan adalah 800 , jumlah populasi lebah jantan adalah 300 , batas kapasitas spermatheca adalah 100 dan royal jelly bernilai 0.5 .

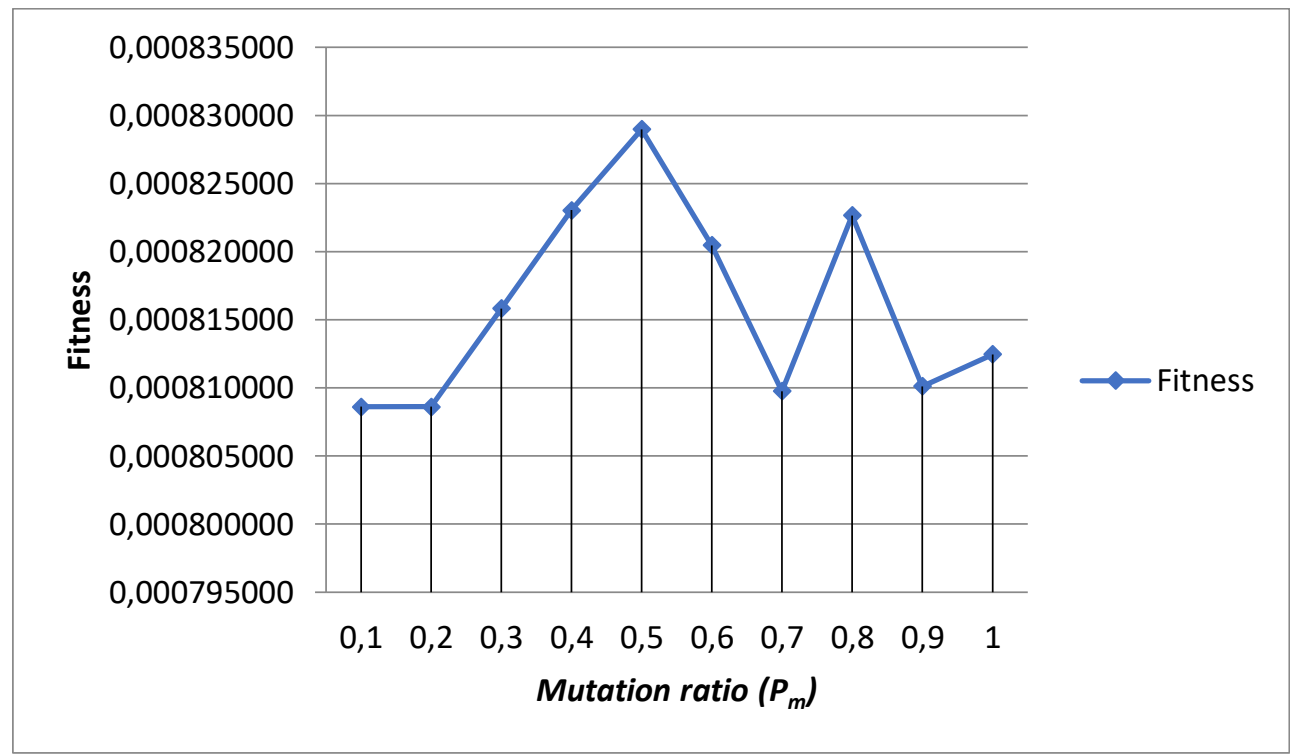

Gambar 5. Grafik Pengaruh Nilai Mutation Ratio Terhadap Nilai Fitness

Gambar 5 menujukkan hasil dari pengujian pengaruh nilai $P_{m}$ terhadap nilai fitness. ketika bernilai 0.1 , nilai fitness yang diperoleh merupakan nilai yang paling rendah yaitu 0.000808620 . nilai fitness tertinggi terdapat pada $P_{m}$ bernilai 0.5 dengan nilai 0.000828974 . Hal ini menunjukkan kasus VRPTW pada kasus pencarian rute wisata Malang membutuhkan frekuensi mutasi genotype yang tidak terlalu tinggi agar individu dari generasi ke generasi tidak terlalu banyak berubah, tetapi juga membutuhkan frekuensi mutasi genotype yang tidak terlalu rendah agar variasi individu berkembang dengan cepat dengan $P_{m}$ yang bernilai 0.5 .

\section{Kesimpulan}

Mengacu pada hasil pengujian yang telah dilakukan, kesimpulan yang didapat dari penelitian ini adalah:

1. Algoritma Honey Bee Mating Optimization (HBMO) dapat digunakan untuk menyelesaikan masalah Vehicle Routing Problem with Time Windows (VRPTW) pada kasus pencarian rute wisata Malang.

2. Parameter-parameter algoritma HBMO yang digunakan dalam mengoptimalkan pemilihan rute wisata Malang dengan konsep VRPTW adalah sebagai berikut:

- Jumlah generasi atau iterasi yang optimal adalah sejumlah 800 generasi dengan ratarata nilai fitnsess sebesar 0.000816378 . 
- Jumlah populasi lebah jantan yang optimal adalah sejumlah 300 ekor dalam satu generasi dengan rata-rata nilai fitness sebesar 0.000817393 .

- Jumlah kapasitas spermatheca yang optimal adalah sebesar 100, dengan rata-rata nilai fitness sebesar 0.000828974 .

- $\quad$ Nilai mutation ratio $\left(P_{m}\right)$ yang optimal adalah senilai 0.5 dengan rata-rata nilai fitness sebesar 0.000828974

\section{Notasi}

M : jumlah lebah jantan

Nsperm : :kapasitas spermatheca

$P_{m} \quad$ : mutation ratio

$\varepsilon \quad$ : variasi muatasi/ royal jelly

\section{Referensi}

[1] Bidang Informasi Publik. (2017, 7 Agustus). Kota Malang Optimis Jumlah Kunjungan Wisman Meningkat. Malangkota. Retrieved from https://malangkota.go.id

[2] Suprayogi, D. A., \& Mahmudy, W. F. (2015). Penerapan algoritma genetika traveling salesman problem with time window: Studi kasus rute antar jemput laundry. Jurnal Buana Informatika, 6(2).

[3] Gunadi, F. A. (2017). Penerapan Algoritma Pigeon Inspired Optimization untuk menyelesaikan Capacitated Vehicle Routing Problem.

[4] Marinakis, Y., Marinaki, M., \& Dounias, G. (2010). Honey Bees Mating Optimization algorithm for large scale vehicle routing problems. Natural Computing, 9(1), 5-27.

[5] Amri, M., Rahman, A., \& Yuniarti, R. (2014). Penyelesaian Vehicle Routing Problem dengan Menggunakan Metode Nearest Neighbor (Studi Kasus: MTP Nganjuk Distributor PT. Coca Cola). Jurnal Rekayasa dan Manajemen Sistem Industri, 2(1), p36-45.

[6] Saputri, M. W., Mahmudy, W. F., \& Ratnawati, D. E. (2015). Optimasi Vehicle Routing Problem with Time Window (VRPTW) Menggunakan Algoritma Genetika pada Distribusi Barang. Jurnal Mahasiswa PTIIK Universitas Brawijaya, 5(12), 1-9.

[7] Nugraha, D. C. A., \& Mahmudy, W. F. (2015). Optimasi Vehicle Routing Problem With Time Windows Pada Distribusi Katering Menggunakan Algoritma Genetika. SESINDO 2015, 2015.

[8] Azhar, Y., Maskur, M., \& Kholimi, A. S. (2012). Metode Hybrid Maximum Tsallis Entropy dan Honey Bee Mating Optimization untuk Pencarian Multilevel Threshold pada Citra Grayscale. JUTI: Jurnal IImiah Teknologi Informasi, 10(1), 34-39. 
REPOSITOR, Vol. 2, No. 4, April 2020: 495-502 